\title{
O SALÁRIO POR PEÇA NA CAFEICULTURA DA REGIÃO GEOGRÁFICA INTERMEDIÁRIA DE VARGINHA-MG
}

\section{THE PIECE WAGE IN COFFEE CULTIVATION IN THE INTERMEDIATE GEOGRAPHICAL REGION OF VARGINHA-MG}

\author{
Lucas Guedes Vilas Boas \\ Centro Federal de Educação Tecnológica de Minas Gerais, Nepomuceno, MG, Brasil \\ lucasguedes@cefetmg.br
}

Fábio Luiz Tezini Crocco Instituto Tecnológico de Aeronáutica, São José dos Campos, SP, Brasil crocco@ita.br

\section{Resumo}

A categoria salário por peça, analisada por Karl Marx em $O$ Capital, é atual para discutir o trabalho na cafeicultura da região geográfica intermediária de Varginha, situada no sul do estado de Minas Gerais, a qual possui sua economia estruturada na produção cafeeira há mais de um século. Durante o período da colheita, a maioria dos apanhadores de café é paga pela produtividade de seu trabalho, isto é, pelo número de medidas de café colhidas, caracterizando o salário por peça. Destarte, foi avaliada a maneira como esta modalidade de remuneração promove a intensificação e a exploração do trabalho na conjuntura agrária sul-mineira. A pesquisa bibliográfica, a análise documental, o trabalho de campo e as entrevistas semiestruturadas forneceram o arcabouço teórico-metodológico para a realização deste estudo.

Palavras-chave: Salário por peça. Cafeicultura. Trabalho. Minas Gerais. Região Geográfica Intermediária de Varginha.

\begin{abstract}
The piece wage category, analyzed by Karl Marx in The Capital, is current to discuss labour in coffee cultivation in the intermediate geographic region of Varginha, located in the south of Minas Gerais state, which has its economy structured in the coffee production for more than a century. During the harvest period, most coffee pickers are paid for the productivity of their work, i.e. for the amount of coffee harvested, characterizing the salary per piece. Thus, we analyzed the way in which this type of remuneration promotes the intensification and exploitation of labour in the agrarian conjuncture of southern Minas Gerais. Bibliographical research, documentary analysis, fieldwork and semistructured interviews provided the theoretical-methodological framework for this study.
\end{abstract}


Keywords: Piece wage. Coffee cultivation. Labour. Minas Gerais. Intermediate Geographical Region of Varginha.

\section{Introdução}

A cafeicultura movimenta a economia sul-mineira e é importante fonte de renda para muitos trabalhadores, tanto proprietários fundiários, quanto safristas. A colheita do café, atividade que demanda expressiva quantidade de mão de obra, ocorre principalmente entre os meses de maio e setembro, atraindo significativa força de trabalho oriunda dos municípios sul-mineiros e de outras regiões, como o Norte de Minas e a Bahia (SANTOS, 2011; RIBEIRO, 2014; VALE, CALDERARO, FAGUNDES, 2014; VILAS BOAS, 2016).

Em virtude de seu relevo mais ondulado, o qual dificulta a mecanização da agricultura, os municípios sul-mineiros empregam maior quantidade de trabalhadores temporários e permanentes nas lavouras cafeeiras (VALE, CALDERARO, FAGUNDES, 2014). Ademais, a região Sul de Minas, a qual abrange a região geográfica intermediária de Varginha, possui condições pedológicas, climáticas e geomorfológicas ideais à cafeicultura, atividade que atraiu significativo contingente de imigrantes nacionais e estrangeiros para os seus municípios, sobretudo no final do século XIX e no início do período novecentista. Atualmente, a região é a maior produtora da rubiácea no estado, com vários municípios no rol dos maiores produtores de café do país (VILAS BOAS, 2016).

O maior emprego da força de trabalho ocorre nos períodos de safra e, portanto, caracteriza relações laborais e contratações sazonais e temporárias. A mão de obra mais abundante realiza sua atividade de forma manual e semimecanizada e a principal forma de pagamento é o salário por peça, pautado na retribuição por produtividade (CROCCO et al., 2017). Essa forma de salário foi analisada por Karl Marx em sua obra clássica $O$ Capital, no Capítulo 19 do Livro I, e nela encontra-se um importante arcabouço teórico e crítico que proporciona subsídios para a análise da realidade vivenciada atualmente em muitos setores produtivos, como é o caso do trabalho na produção cafeeira da região geográfica intermediária de Varginha. 
Mapa 1: Localização dos Municípios Estudados na Região Geográfica Intermediária de Varginha
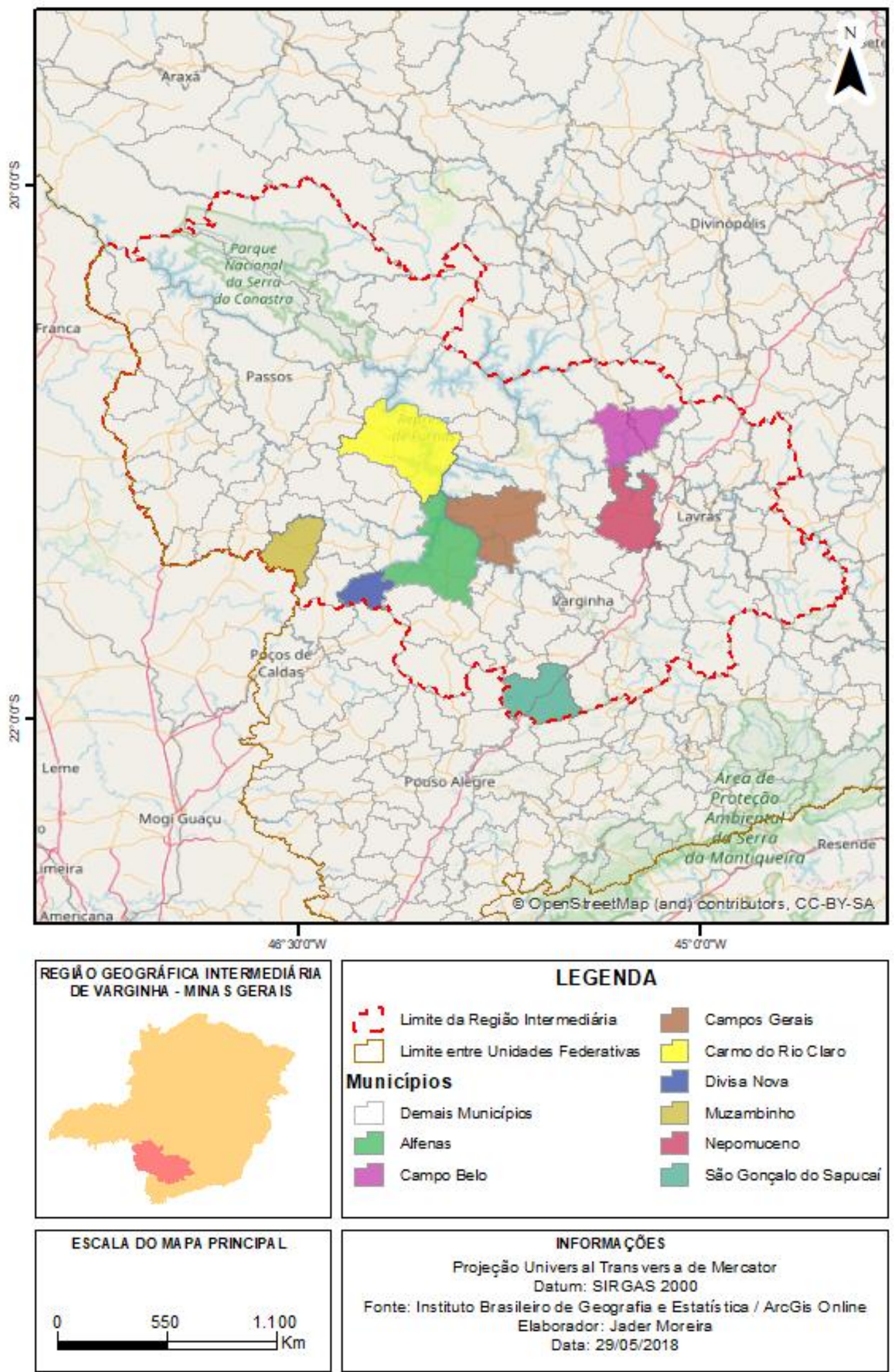
A classificação do território brasileiro em regiões geográficas imediatas e intermediárias efetuada pelo IBGE (2017), com o apoio de órgãos estaduais, contempla as principais características associadas aos municípios discutidos neste estudo, considerando suas singularidades. Dentre os municípios analisados, Alfenas, Campo Belo, Campos Gerais, Carmo do Rio Claro, Divisa Nova, Muzambinho, Nepomuceno e São Gonçalo do Sapucaí se localizam na região geográfica intermediária de Varginha, área de vultosa produção cafeeira, a qual está representada pelo mapa 1. Nos dizeres do $\operatorname{IBGE}(2017$, p. 19):

\begin{abstract}
As Regiões Geográficas Intermediárias correspondem a uma escala intermediária entre as Unidades da Federação e as Regiões Geográficas Imediatas. [...] As Regiões Geográficas Intermediárias organizam o território, articulando as Regiões Geográficas Imediatas por meio de um polo de hierarquia superior diferenciado a partir dos fluxos de gestão privado e público e da existência de funções urbanas de maior complexidade.
\end{abstract}

De antemão, o IBGE (2017) determinou que as regiões geográficas intermediárias fossem constituídas por no mínimo duas regiões geográficas imediatas, suas unidades fundamentais e indivisíveis, cujos municípios devem pertencer à mesma unidade federativa. Neste sentido, a agregação das regiões geográficas imediatas, que correspondem às microrregiões, foi a base para a composição das regiões geográficas intermediárias, as quais se enquadram na categoria das mesorregiões.

Nesta perspectiva, este estudo coadunou pesquisa bibliográfica, análise documental, entrevistas semiestruturadas e trabalho de campo, o qual foi efetivado nos anos de 2015, 2016, 2017 e 2018. A pesquisa bibliográfica e a análise documental enfocaram publicações científicas e documentos oficiais relativos aos municípios integrantes da região geográfica intermediária de Varginha. Já as entrevistas semiestruturadas foram realizadas com proprietários fundiários e colhedores de café no município de Nepomuceno.

O trabalho foi dividido em três partes, com exceção da introdução e das considerações finais. Uma baseada nas distintas formas de remuneração na agricultura brasileira, com ênfase no pagamento por produtividade; a segunda pautada no debate teórico do salário por peça, realizado na obra $O$ Capital de Karl Marx; e outra focada nas consequências dessa forma de assalariamento para as condições de trabalho. Assim, a investigação procurou compreender as características do salário por peça na cultura 
cafeeira da região e analisar criticamente como essa forma de assalariamento condiciona um modus operandi laboral e de exploração da força de trabalho.

\section{Os salários e o pagamento por produtividade na agricultura brasileira}

Historicamente, a conjuntura econômica mundial influencia diretamente os salários pagos na cafeicultura. Segundo Stolcke (1986), durante a crise da cafeicultura brasileira decorrente da quebra da Bolsa de Valores de Nova York, os cafeicultores diminuíram expressivamente os salários pagos aos trabalhadores para tentarem sobreviver aos efeitos da crise.

De acordo com Stolcke (1986), na vigência do regime de colonato, o trabalho na cafeicultura abrangia o familiar e o individual e o pagamento era realizado por intermédio do salário por tarefa e por produção, ao qual Marx (2013) denomina salário por peça. Os colonos trabalhavam tanto nas lavouras cafeeiras para os proprietários das terras, quanto produziam gêneros para o autoconsumo do núcleo familiar. No início do século XX, em virtude do aumento do preço venal da rubiácea nos mercados internacionais, muitos proprietários fundiários proibiram que os colonos cultivassem outros gêneros em consórcio com o café, mas não restringiram completamente a produção de víveres para autoconsumo. Doravante o decênio de 1950, os proprietários de terras passaram a usar as terras adjacentes aos cafezais - outrora destinadas ao plantio de gêneros destinados à alimentação do colonato - para o cultivo comercial de outros víveres agrícolas, repercutindo em prejuízos para os colonos, uma vez que ficaram sem terras disponíveis para o autoabastecimento da família.

Com a promulgação do Estatuto do Trabalhador Rural (ETR) em 1963, muitos fazendeiros impediram que os trabalhadores colonos cultivassem alimentos para o autoconsumo familiar, com o objetivo de que abdicassem da indenização decorrente do pagamento dos direitos trabalhistas, enquanto outros demitiram os colonos e pagaram a indenização. Com a desestruturação do regime de colonato, muitos proprietários fundiários contrataram assalariados permanentes para o trabalho agrícola, uma vez que a mecanização ainda era incipiente no decênio de 1960 (STOLCKE, 1986). Além disso, disseminaram-se as formas de trabalho temporárias e remuneradas por produtividade (OLIVEIRA, 2007). 
Segundo Silva (1999) e Alves (2006), o salário por peça é predominante como remuneração nas colheitas de cana-de-açúcar, café e laranja. Esta forma de pagamento por produtividade não demanda investimentos em capital constante, intensifica a concorrência entre os trabalhadores e aumenta a produtividade agrícola, além de realçar as diferenças de força, destreza e habilidade entre os trabalhadores. De acordo com Guanais (2016), muitas das atividades assalariadas rurais/agrícolas são remuneradas por intermédio do salário por peça, em virtude de sua própria natureza, pois algumas decorrem do período de safra/colheita, algo temporário.

Guanais (2016) mostra que quando a remuneração do trabalho no corte da canade-açúcar passou a se basear na tonelada, houve a minoração do controle dos trabalhadores sobre a quantidade produzida, pois quando o salário por peça era determinado pelo número de metros ou braças de cana colhidas, havia mais controle sobre o quantum produzido. No entanto, há muito tempo, desde os anos 1960, existem diversas denúncias de fraudes e roubos no momento da pesagem e/ou da medição da cana colhida, com o intento de reduzir o montante pago aos cortadores. Ademais, o pagamento por tonelada contraria dois direitos assegurados a todos os trabalhadores, uma vez que os cortadores de cana não possuem um critério objetivo que determine o ganho auferido com o trabalho, tampouco fiscalizam e/ou conferem sua produção.

Já na cafeicultura, assim como em outros setores agrícolas, o cenário é diferente, pois os apanhadores possuem conhecimento sobre a forma de pagamento, visto que recebem por medida de café colhida. Tal situação não impede a exploração de sua força de trabalho, mas dificulta possíveis fraudes na mensuração da quantidade colhida.

O pagamento por produtividade ocasionou superexploração do trabalho, invalidez permanente e/ou morte em trabalhadores das lavouras canavieiras no estado de São Paulo. O aumento das metas de produção e a intensificação do trabalho majoraram a exploração e a insalubridade nos canaviais paulistas. Ademais, a mecanização da produção canavieira diminuiu as vagas temporárias de trabalho, aumentou o desemprego agrícola/rural e colaborou para a intensificação da exploração da mão de obra remanescente (ALVES, 2006; SILVA, BUENO, MELO, 2014; SILVA, 2016). Acerca do tema, Alves (2006) propôs a proibição do pagamento por produtividade e, consequentemente, do salário por peça, na agricultura brasileira, com o propósito de diminuir a exploração, o adoecimento e a mortalidade dos trabalhadores agrícolas no país. 
A tática de premiar os trabalhadores que atingirem as metas predeterminadas no corte da cana promoveu o aumento da produtividade e a intensificação do trabalho nos canaviais paulistas. Entretanto, quanto mais objetivos não forem cumpridos, mais o valor monetário das bonificações é reduzido (SILVA, BUENO, MELO, 2014). Além disso, os cortadores que não cumprem as metas preestabelecidas são dispensados, o que causa prejuízos financeiros e dificuldade em obter novos postos de trabalho (SILVA, 2016). No tocante ao assunto, Guanais (2016) afirma que, no âmbito do pagamento via salário por peça, quando a capacidade média de rendimento do trabalho não é atingida, é habitual a ocorrência de demissões. Sublinha-se que o salário pago aos trabalhadores canavieiros geralmente não supre todas as necessidades básicas do núcleo familiar (SILVA, 2016).

Não obstante, o trabalho relacionado à cultura canavieira é, em geral, insalubre e perigoso, em virtude de diversos fatores, como o risco de picada e ataque de animais peçonhentos, as temperaturas elevadas, as patologias respiratórias e o contato com materiais nocivos à saúde, como os agrotóxicos. Sob essa perspectiva, a aplicação dos praguicidas é uma atividade insalubre, uma vez que, além do grande peso das bombas costais, causa alergias, náuseas, desmaios, enxaquecas, entre outros malefícios (SILVA, BUENO, MELO, 2014).

\section{Marx e o salário por peça}

Primeiramente, cabe considerar que o salário por peça e o salário por tempo são, ambos, formas que representam o valor ou preço da força de trabalho. Portanto, a essência do salário é a mesma e está pautada na força de trabalho, no trabalho vivo que objetiva e agrega valor à mercadoria. Nesse sentido, Marx afirma que "a diferença de forma no pagamento do salário não modifica em nada a essência deste último, ainda que uma forma possa ser mais favorável que a outra para o desenvolvimento da produção capitalista" (MARX, 2013, p. 760). Por outro lado, se o salário por tempo mede o valor da peça pelo tempo de trabalho, o salário por peça mede o trabalho gasto pelo trabalhador através do número de peças que ele produziu.

Portanto, "no salário por tempo, o trabalho se mede por sua duração imediata; no salário por peça, pela quantidade de produtos em que o trabalho se condensa durante um tempo determinado" (MARX, 2013, p. 761). Apesar da diferença, todo trabalho se efetiva 
num tempo específico e é a relação tempo/produção que determina a taxa de produtividade de ambas as formas de salário. Marx considera, portanto, que o salário por peça "não é mais do que uma forma modificada do salário por tempo" (MARX, 2013, p. 760).

Essa primeira consideração é importante, porque o salário por peça pode falsamente levar à interpretação de que, nessa modalidade, o pagamento se efetiva por produto ou pela capacidade de produção sem relação com o trabalho humano executado numa determinada fração de tempo. Ou seja, o salário por peça não é a retribuição por produto, mas pelo trabalho que o produz. A falsa ideia de que se paga o produto pode imputar a interpretação de que há uma troca na esfera da circulação, como a compra e venda de mercadorias e, consequentemente, pode representar incorretamente uma troca justa e equilibrada segundo as leis de mercado. Essa perspectiva fetichizada oculta os conflitos entre capital e trabalho e a exploração da força humana e, portanto, dissimula as estratégias de intensificação e de expansão da jornada de trabalho relacionadas ao salário por peça.

Essa aparência é desfeita ao descortinar o fato de que o valor pago por peça é também determinado pelo tempo necessário para sua elaboração. Marx demonstra esse fato a partir de dois argumentos: o primeiro refere-se à presença, ao mesmo tempo, das duas formas de pagamento nos mesmos ramos industriais ${ }^{1}$, pois representam estratégias salariais distintas para fazer uso da força de trabalho a partir de suas vantagens específicas para o capital; o segundo diz respeito à produtividade variável do trabalho que gera uma quantidade também variável de produtos por tempo e, consequentemente, faz variar o salário por peça. Assim, a partir do cálculo da variação da produtividade de peças/tempo, Marx conclui que "o salário por peça é rebaixado na mesma proporção em que aumenta o número das peças produzidas durante o mesmo período de tempo ou, portanto, em que diminui o tempo de trabalho empregado na mesma peça" (MARX, 2013, p. 766).

Dentre os motivos que definem a utilização do salário por tempo ou do salário por peça estão fatores econômicos e não econômicos. Predominam as decisões pautadas em fatores econômicos, como, por exemplo, a forma de salário que melhor promove a diminuição de custos e a maior produtividade para o empregador. Os fatores não econômicos podem ser exemplificados pela influência cultural (ou mesmo étnica) numa dada localidade ou num setor profissional específico que define práticas e hábitos produtivos. Relacionada ao fator econômico está a utilização do salário por peça, por 
exemplo, em tipos específicos de trabalho ou etapas do processo produtivo que, consequentemente, geram maior rentabilidade ao capital. Este é o caso do trabalho na indústria têxtil (confecção de vestuário), na colheita de muitas culturas agrícolas e na atividade do artista. Outros tipos de trabalho, por razões técnicas, ou por exigirem maior qualificação, são geralmente contratados por tempo. Entretanto, é um erro pensar que os fatores econômicos e não econômicos estão isolados, pois ambos se relacionam para influenciar a escolha do tipo de salário.

Outra peculiaridade que caracteriza o salário por peça é a forma com que se efetiva o controle do trabalho e de sua qualidade. Na verdade, essa forma-salário dispensa grande parte da supervisão laboral pelo fato de o esforço e a qualidade serem medidos pelo resultado final, ou melhor, pelo produto. Assim, as formas de controle de qualidade e supervisão do trabalho não se pautam tanto nos meios, nos processos e nas formas de execução da atividade, mas nos fins. Sobre essa questão, Marx destaca que "a qualidade do trabalho é controlada, aqui, pelo próprio produto, que tem de possuir uma qualidade média para que se pague integralmente o preço de cada peça” (MARX, 2013, p. 761). No entanto, como destaca o autor, essa qualidade média é demasiado subjetiva e incerta e torna o salário por peça estratégia de descontos salariais e de fraudes capitalistas. Além disso, é um erro acreditar que a forma de salário por peça dispense supervisão por completo, não obstante, são realizadas outras formas de controle, que nos tempos atuais, de constante reestruturação produtiva, têm sido revigoradas e amplamente utilizadas ${ }^{2}$.

Por um lado, em determinados setores há o controle constante para averiguar se está sendo produzido "um mínimo determinado de trabalho diário" (MARX, 2013, p. 761), sob pena de dispensa e substituição do trabalhador. Assim, o sistema de produção pautado no salário por peça é controlado pela produtividade média do trabalhador num tempo determinado e, contrariamente, a intensidade do trabalho no sistema do salário por tempo é medida e condicionada em comparação com a produtividade do salário por peça. Ou seja, por meio do salário por peça em que o trabalhador se esforça o máximo possível para aumentar seu salário, define-se os parâmetros da intensidade empregada no salário por tempo.

Por outro, essa forma salarial facilita a atuação de intermediários entre o capitalista e o assalariado, que atuam, predominantemente, como controladores e agentes intensificadores do trabalho. 
O subarrendamento do trabalho ou a presença de intermediários é comum nas atividades em que os trabalhadores são pagos pelo salário por peça. $\mathrm{O}$ rendimento do intermediário depende da produtividade dos trabalhadores por ele agenciados e controlados. O que leva Marx a denominar os intermediários de parasitas é o fato de seus ganhos virem "exclusivamente da diferença entre o preço do trabalho pago pelo capitalista e a parte desse preço que eles deixam chegar efetivamente ao trabalhador" (MARX, 2013, p. 762). É por esse motivo que na Inglaterra essa relação é denominada de sistema sudorífero (sweating-system). Outra modalidade de intermediário é o caso do chefe do grupo ou trabalhador principal, que agencia e paga a mão de obra de uma equipe de trabalhadores que atuam sob sua supervisão. Seu rendimento advém da quantidade de peças que ele mesmo produz, mais uma parte percentual da produtividade de sua equipe. Conforme afirma Marx, "a exploração dos trabalhadores pelo capital se efetiva, aqui, mediante a exploração do trabalhador pelo trabalhador" (MARX, 2013, p. 762).

Apesar da presença de formas típicas de controle e de intermediários nessa modalidade, o salário por peça naturalmente torna o trabalhador um explorador de si mesmo, pois de forma imediata seu rendimento depende do emprego intensivo de suas forças e da utilização do maior tempo possível para produzir o máximo que tiver condição. Portanto, o trabalhador é seu próprio algoz. É ele mesmo, de forma ativa, que controla e impõe a si a maior intensidade e a mais longa jornada de trabalho possível.

A aparente autonomia gerada pelo salário por peça, proporcionada pelo maior espaço de ação, tende a desenvolver nos trabalhadores os sentimentos de liberdade, individualidade, independência e autocontrole, os quais se coadunam com os imperativos morais do mercado e consagram a perspectiva individualista do trabalho e, consequentemente, a lógica da concorrência. Assim, o salário por peça instaura um espírito de competição. Essa competição tende a rebaixar o salário geral dos trabalhadores e é economicamente benéfica ao empregador que indiretamente aprecia o emprego de maior ritmo, intensificação e expansão da jornada de trabalho.

Dado o salário por peça, é natural que o interesse pessoal do trabalhador seja o de empregar sua força de trabalho o mais intensamente possível, o que facilita ao capitalista a elevação do grau normal de intensidade. É igualmente do interesse pessoal do trabalhador prolongar a jornada de trabalho, pois assim aumenta seu salário diário ou semanal. Com isso, ocorre a reação já descrita no caso do salário por tempo, abstraindo do fato de que o prolongamento da jornada de trabalho, mesmo mantendo-se constante a taxa do salário por peça, 
implica, por si mesmo, uma redução no preço do trabalho. (MARX, 2013, p. 762-763).

O salário por peça carrega consigo a perspectiva de instabilidade laboral ao trabalhador. A rigorosidade dessa exploração de si é maior em atividades temporárias e sazonais que findadas impõem ao trabalhador a condição de desemprego. Este fenômeno é percebido no fato de o trabalhador não conseguir prognosticar sua produção num determinado período de tempo e, consequentemente, não saber qual será seu salário. Ou ainda, caso o trabalhador não consiga ou fique impedido de trabalhar, por qualquer motivo, estará desassistido. A instabilidade ocorre também em virtude de as atividades, que geralmente são retribuídas pelo salário por peça, serem temporárias e sazonais.

Marx (2013, p. 765) discute essa instabilidade ao demonstrar que num curto espaço de tempo, o trabalhador sazonal/temporário que atua segundo o trabalho por peça, pode ter uma retribuição financeira maior do que outro atuando no sistema do salário por tempo, mas aponta que, por causa do tempo parado (inativo), os ganhos adicionais se equilibram, proporcionando a esse trabalhador instabilidade e, comparativamente num longo prazo, menores salários ${ }^{3}$. E, consequentemente, é comum que o vínculo contratual das atividades que promovem o salário por peça seja mais frágil ou inexistente, impondo ao trabalhador a condição de informalidade. Por fim, sobre a precariedade relacionada ao salário por peça, Marx (2013, p. 765) cita as considerações de Malthus sobre fatos publicados pelo Parlamento Inglês: "Confesso que vejo com desagrado a grande difusão da prática do salário por peça. Um trabalho efetivamente duro que se estenda por $12 \mathrm{ou}$ 14 horas por dia, ou por períodos ainda mais longos, é demasiado para um ser humano".

Da exposição e discussão das características da forma do salário por peça, Marx afirma que esta "é a forma de salário mais adequada ao modo de produção capitalista" (MARX, 2013, p. 764). Tal adequação está relacionada à melhor forma de reprodução e acumulação de capital que depende da melhor e mais intensa exploração da força de trabalho. O fetiche da autonomia, da liberdade e da competição, proporcionado por esta forma salarial, tende a ocultar a intensidade da exploração. Entretanto, há situações em que o trabalhador percebe as artimanhas e desenvolve formas de resistência. Marx aponta três situações que proporcionam ao trabalhador uma maior consciência de sua exploração:

Ou porque o capitalista aproveita o pretexto para reduzir efetivamente o preço do trabalho, ou porque o incremento da força produtiva do trabalho é acompanhado de uma maior intensidade deste último. Ou, então, porque o trabalhador leva a sério a aparência do salário por peça, como se lhe fosse pago 
seu produto, e não sua força de trabalho, e se rebela, portanto, contra um rebaixamento do salário, que não corresponde ao rebaixamento do preço de venda da mercadoria. (MARX, 2013, p. 766).

Às três formas elencadas soma-se o fato de os trabalhadores vigiarem cuidadosamente os processos produtivos e os custos de produção e, consequentemente, serem capazes de calcular os lucros de seus patrões (MARX, 2013, p. 767). Tal cálculo desperta o trabalhador para sua condição de explorado ao perceber a diferença do seu salário em comparação com os lucros de seu empregador. A diferença entre a quantidade de valor produzida e o que é pago ao trabalhador tende a ser muito grande e, comumente, lhe causa indignação.

Nos dizeres de Marx (2013), o salário por peça é um sistema articulado de exploração e opressão, constituindo uma artimanha capitalista para o pagamento de diminutas remunerações aos trabalhadores e o prolongamento de suas jornadas de trabalho.

\section{O salário por peça e as condições de trabalho na cafeicultura da região geográfica intermediária de Varginha-MG}

Nos trabalhos caracterizados pelo pagamento do salário por peça, sabe-se, através da experiência prática, a produtividade média do trabalho (MARX, 2013, p. 767). Este panorama é semelhante ao da cafeicultura nepomucenense, pois os safristas estimam o futuro pagamento com base no número médio de medidas de café 4 colhidas e no valor pago por cada medida.

Vale, Calderaro e Fagundes (2014) afirmam que a maioria da força de trabalho utilizada na cafeicultura sul-mineira é contratada temporariamente, apenas para o período da safra. Esses trabalhadores são denominados apanhadores de café ou safristas. Seu pagamento geralmente é determinado pela produtividade, acarretando em intensificação das jornadas de trabalho. Nos tempos hodiernos, a conjuntura nepomucenense é próxima à realidade dos demais municípios do sul de Minas Gerais, pois a maioria da mão de obra empregada na cafeicultura é contratada de forma temporária.

No sul de Minas Gerais, os médios e grandes proprietários agrícolas engendram o pagamento pela quantidade de café colhida como estratagema para majorar a produtividade de suas lavouras. Todavia, ao passo que seus lucros são ampliados, ocorre 
a extenuação da mão de obra empregada na safra e a disseminação de moléstias ocasionadas pelas extensas e deletérias jornadas de trabalho (COALIZAÇÃO DO CAFÉ, 2004; RIBEIRO, 2014). Em pesquisa efetivada no município de Campo Belo, Ribeiro (2014) constatou que as patologias respiratórias e as lesões por esforço repetitivo são as enfermidades mais comuns entre os apanhadores de café. Além disso, cabe destacar que os colhedores ficam expostos aos acidentes, às picadas de animais peçonhentos e às intempéries em suas rotinas de trabalho (VILAS BOAS, 2016; CROCCO et al., 2017).

A ausência dos equipamentos de proteção individual (EPIs) durante o labor nos cafezais, verificada nos municípios de Campo Belo (RIBEIRO, 2014), Campos Gerais (PEREIRA, 2011), Divisa Nova (RAIMUNDO, VALE, 2016), Nepomuceno (CROCCO et al., 2017), São Gonçalo do Sapucaí e Silvianópolis (MELLO, SILVA, 2013) agrava os riscos aos quais os colhedores se submetem em seu expediente de trabalho. Na maioria dos casos, com o intuito de reduzir os gastos com mão de obra, os proprietários agrícolas não fornecem todos os EPIS necessários à colheita. Já em outras situações, os próprios colhedores optam pela não utilização dos acessórios de segurança, pois consideram que seu uso estorva a jornada de trabalho e diminui a produtividade durante a apanha.

A contaminação por pesticidas é comum na cafeicultura sul-mineira, inclusive entre os colhedores que são remunerados por meio desta modalidade de pagamento. Em pesquisa realizada no ano de 2011, Mello e Silva (2013) identificaram que 59,2\% dos trabalhadores temporários pesquisados apresentaram algum sintoma de intoxicação subaguda durante o período da colheita cafeeira nos municípios de São Gonçalo do Sapucaí e Silvianópolis, nos quais prepondera a mão de obra sazonal na apanha do café. Ademais, em seu estudo, diversos trabalhadores relataram internações anteriores em virtude da intoxicação pelo uso de praguicidas.

Já em Nepomuceno, vários indivíduos manifestaram mal-estar, alergia ou dores estomacais após a aplicação dos agrotóxicos entre 2014 e 2016. Em alguns casos, ocorreram internações devido à intoxicação pelos pesticidas, especialmente em virtude do contato com o Roundup, cujo componente ativo é o glifosato, o herbicida mais utilizado na cafeicultura nepomucenense (VILAS BOAS, 2017). Dentre seus malefícios, pode-se citar a ocorrência de enfermidades neurológicas, neoplasias e patologias respiratórias ou cardiológicas (SAMSELL, SENEFF, 2015). 
Em virtude da necessidade de ampliação dos rendimentos obtidos, uma vez que o trabalho na colheita da rubiácea é temporário e o pagamento varia de acordo com a produtividade, os apanhadores de café frequentemente prolongam e intensificam suas jornadas de trabalho. A não utilização dos EPIs e o contato direto com os praguicidas contribuem para a precarização das condições de trabalho na agricultura, mas são comuns entre os colhedores, os quais aumentam a insalubridade de seu trabalho visando acréscimos em seus pagamentos. Como no salário por peça o trabalhador é remunerado de acordo com a produtividade de seu trabalho, a extensão e a intensificação das jornadas diárias de trabalho, a ausência dos EPIs e a aplicação dos agrotóxicos, práticas cujo principal objetivo é o aumento dos rendimentos auferidos na apanha, culminam em sérios agravos à saúde dos trabalhadores.

Conforme discutido anteriormente, o salário por peça é minorado proporcionalmente ao aumento da quantidade de peças produzidas num mesmo intervalo de tempo. Neste cenário, o capitalista frequentemente se aproveita do crescimento da produtividade para reduzir os salários pagos (MARX, 2013). Baseada nas considerações de Marx (2013), Guanais (2016, p. 81) afirma que:

a produtividade variável do trabalho também faz variar o salário por peça, uma vez que este é a expressão do preço de um tempo determinado de trabalho. Ou seja, se, devido ao aumento da produtividade do trabalho a mesma jornada passasse a fornecer, por exemplo, o triplo de peças que antes, o salário por peça cairá, já que cada peça representará, agora, menos horas de trabalho para ser produzida do que antes.

A introdução da derriçadeira portátil ${ }^{5}$ de grãos de café na colheita dos municípios sul-mineiros, incluindo aqueles pertencentes à região geográfica intermediária de Varginha, ocasionou o aumento da produtividade cafeeira municipal, reverberando em ampliação da mais-valia ${ }^{6}$ extraída no trabalho agrícola. De acordo com Coulis (2011), o emprego desta máquina durante a apanha repercute em uma produtividade equivalente à de aproximadamente seis trabalhadores que efetuam a colheita de forma manual, método ainda predominante em território nacional (MERGULHÃO, 2017).

A relação entre o aumento da produtividade do trabalhador e a diminuição do salário por peça é exemplificada, na região geográfica intermediária de Varginha, pelo fato de o preço da medida de café colhido variar de acordo com a qualidade da roça e a quantidade de frutos nas plantas. Ou seja, se as plantas de café possuem muitos frutos e boas condições para a colheita, o preço da medida cai e, contrariamente, se o cafezal está 
em más condições e possui poucos frutos nas plantas, o preço aumenta. Por trás da aparente proporção justa de troca no mercado, encontram-se as artimanhas de elevação e diminuição dos preços, segundo os interesses dos empregadores, e de envolvimento dos trabalhadores em um mercado de trabalho que supostamente se regula naturalmente.

Com base em Marx (2013), pode-se ressaltar que o emprego de maquinário e de insumos químicos na agricultura amplia a produtividade e gera maior controle e intensificação do trabalho, ocasionando, respectivamente, a extração de mais-valia relativa e absoluta. Para Marx (2011; 2013), a mais-valia absoluta resulta do sobretrabalho. Assim, quando o proletário tem uma jornada de trabalho superior ao equivalente ao valor de sua força de trabalho, há a apropriação da mais-valia absoluta, a qual decorre do prolongamento temporal das horas ou dias de trabalho. Já a mais-valia relativa é obtida pelo aumento da produtividade do trabalho, o qual comumente deriva de avanços técnicos nos processos de produção e trabalho, resultando em diminuição do valor da mão de obra trabalhadora. Como os salários nominais diminuem e o excedente da produção é aumentado, amplia-se a mais-valia auferida pelo proprietário dos meios de produção. Cabe salientar que ambas as formas da mais-valia não podem ser avaliadas de maneira dissociada, pois são auferidas simultaneamente e possuem estreita relação.

Raimundo e Vale (2016) afirmam que o uso da colheitadeira manual (Figura 1) majorou os rendimentos dos apanhadores durante a colheita no município de Divisa Nova, mas tornou a carga de trabalho ainda mais intensa, pois o peso da derriçadeira varia entre dois e quatro quilogramas. Nesta perspectiva, o preço médio pago pelos safristas na aquisição da máquina foi de aproximadamente setecentos reais ( $\mathrm{R} \$ 700,00)$, valor monetário acessível para muitos trabalhadores. Todavia, apesar do aumento da produtividade, é possível que o preço pago pela medida de café diminua na medida em que a colheitadeira manual seja empregada durante a apanha pela maioria dos apanhadores em Divisa Nova, pois de acordo com Marx (2013), o capitalista usufrui dos acréscimos na produtividade para diminuir as remunerações pagas aos trabalhadores. 
Figura 1: Colheita de Café - Manual x Com a Colheitadeira/Derriçadeira Manual

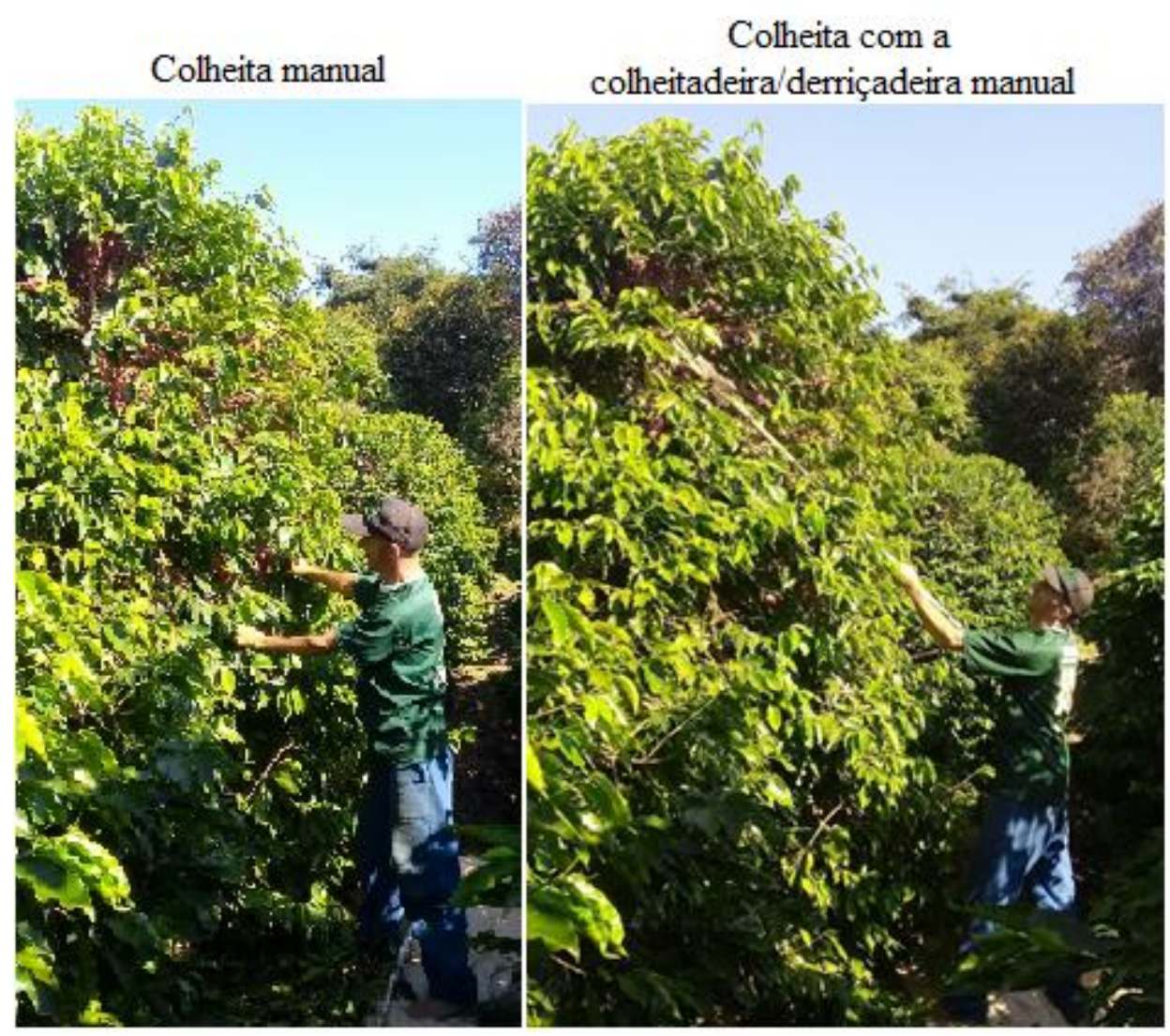

Fonte: Trabalho de Campo, 2018.

Org.: Autores, 2018.

A despeito do crescimento da produtividade cafeeira com a introdução de máquinas no processo produtivo, Libanio, Calderaro e Vale (2011) afirmam que a modernização do campo reduziu a quantidade de empregos no campo sul-mineiro. De acordo com Santos (2014), o processo de modernização da agricultura brasileira afetou a agricultura sul-mineira, com destaque para a cafeicultura, a qual aderiu a um pacote de inovações tecnológicas empregadas no processo produtivo. $\mathrm{O}$ autor mostra que, a partir do decênio de 1970, houve crescimento do uso de insumos agroquímicos e de máquinas agrícolas nas lavouras do município de Alfenas. Esse aumento ocorreu, em partes, devido à ampliação do crédito contraído pelos agricultores. Desta maneira, a capitalização dos agricultores municipais está associada à modernização da cafeicultura alfenense.

Segundo Ribeiro (2014), a mecanização agrícola atingiu a cafeicultura campobelense e, consequentemente, reduziu os postos de emprego no campo, ampliando o desemprego rural. Nesta conjuntura, apesar de saberem que são diariamente explorados, 
os apanhadores de café temem que o patrão adquira mais maquinários, pois sabem que esse processo reverberaria na diminuição dos postos de emprego temporário. Assim, além de toda a exploração típica do pagamento pelo salário por peça, os colhedores ainda convivem anualmente com a incerteza em relação à oferta de trabalho sazonal.

Neste panorama, os grandes cafeicultores de Alfenas afirmaram que a substituição da mão de obra humana pelas máquinas reduziu em no mínimo 50\% os custos da colheita, além de acelerar essa etapa da produção. Assim, muitos produtores preferem mecanizar a produção, provocando a ampliação do desemprego rural no município e, consequentemente, a migração campo-cidade (SANTOS, 2011).

A respeito do assunto, Costa e Poppi (2012) enunciam que a inserção da derriçadeira (Figura 2) na apanha provocou o fechamento de duzentas mil vagas temporárias de trabalho na colheita da rubiácea entre 2006 e 2012. Destarte, pode-se afirmar que a introdução da derriçadeira na colheita cafeeira reduz sensivelmente sua duração, aumenta a produtividade e diminui o número de trabalhadores sazonais necessários. Por conseguinte, também minora o custo total da colheita para o cafeicultor, majorando seus rendimentos. Assim, os gastos com a produção são reduzidos, uma vez que há diminuição dos custos com mão de obra. Simultaneamente, há a ampliação da produtividade das lavouras, dos lucros e da mais-valia apropriada de cada trabalhador pelo proprietário fundiário.

Figura 2: Derriçadeira Portátil de Grãos de Café

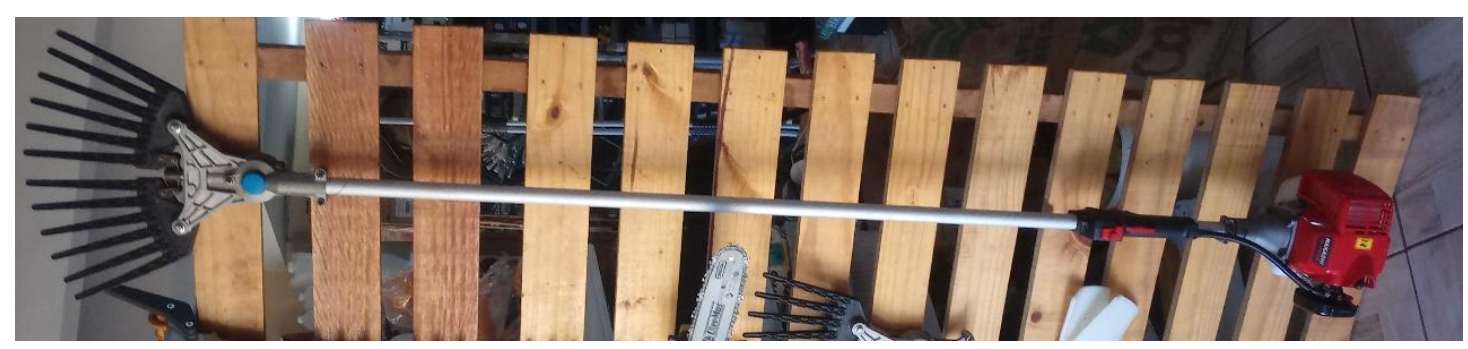

Fonte: Trabalho de Campo, 2018.

Org.: Autores, 2018.

A maioria da força de trabalho empregada na cafeicultura da região geográfica intermediária de Varginha é contratada durante o período da colheita. Nas pequenas propriedades agrícolas, a mão de obra ocupada na apanha de café é constituída principalmente por integrantes do núcleo familiar ou vizinhos, enquanto nas médias e grandes propriedades rurais predomina a contratação de trabalhadores assalariados, os 
quais podem ser do próprio município ou de municípios adjacentes e de outras regiões, como o Norte de Minas, a Bahia e o Norte do Paraná (SANTOS, 2011; VALE, CALDERARO, FAGUNDES, 2014; VILAS BOAS, 2016).

Neste âmbito, o salário por peça, nos períodos de colheita, constitui uma modalidade de pagamento que estimula a mobilidade sazonal de trabalhadores de outras regiões ou unidades federativas, os quais se deslocam principalmente com o objetivo de lograrem bons rendimentos em um curto intervalo de tempo. Em geral, os colhedores vindos de outras regiões são oriundos de áreas muito pobres, como o Sertão Baiano e o Norte de Minas, caracterizadas pelo elevado índice de desemprego e pelos baixos salários pagos. A respeito do assunto, salienta-se que há importantes diferenças entre os apanhadores originários dos municípios sul-mineiros em comparação com os provenientes de outras regiões brasileiras.

Na maioria dos casos, deixam suas famílias nos municípios de origem, devido à sazonalidade da mobilidade realizada. Muitos residem em alojamentos disponibilizados pelos proprietários dos estabelecimentos agropecuários nos quais trabalham. Em geral, essas moradias dispõem de parca infraestrutura e são caracterizadas pela precariedade e insalubridade. Nas situações em que a habitação não é disponibilizada pelos contratantes, as quais correspondem a uma minoria, os trabalhadores se juntam e alugam imóveis de forma temporária.

Referindo-se ao município de Campos Gerais, Pereira (2011) explica que os cafeicultores municipais priorizam a força de trabalho procedente de outras regiões e unidades federativas, pois na avaliação dos proprietários fundiários, os trabalhadores que efetuam a mobilidade sazonal para o trabalho na colheita cafeeira têm maior aptidão física e são mais subordinados às ordens, além de possuírem frágil organização política. A distância dos familiares e amigos, a incipiência de recursos financeiros e o baixo grau de politização são alguns dos fatores que justificam a maior sujeição dos trabalhadores de outros estados e regiões ante sua exploração durante o trabalho na safra cafeeira. Nesta perspectiva, Marx (2013) afirma que o salário por peça transmite uma falsa sensação de autonomia e liberdade aos trabalhadores devido à variabilidade das remunerações e do tempo de trabalho. Assim, de modo geral, esta modalidade de salário consegue abrandar possíveis reivindicações políticas ou movimentos trabalhistas. 
No salário por peça, o valor do trabalho equivale à produtividade obtida e é diretamente determinado pela remuneração paga. Desta maneira, nesta modalidade de pagamento, ocorre a reificação dos trabalhadores, cuja importância é medida pelo seu valor de troca, isto é, através do número de medidas colhidas (LUKÁCS, 2003). Convertidos em mercadorias e concentrados no propósito de colher o maior número possível de medidas ou balaios, os apanhadores de café aceitam, com pouca ou nenhuma resistência, a intensificação e a exploração de sua mão de obra.

Com a flexibilização do trabalho e da produção, a circulação do capital se acelera, favorecendo sua reprodução. Esse processo beneficia os capitalistas e acentua a disparidade entre os detentores dos meios de produção e a classe trabalhadora. Nos tempos hodiernos, o salário por peça se adéqua ao trabalho flexível, pois uma de suas principais características é a falsa aparência de controle do proletariado sobre seu trabalho e a totalidade do processo de produção. O salário por peça, enquanto forma pretérita de pagamento, é revivido ideologicamente na atualidade como a tendência futura de um mercado de trabalho desregulamentado e flexibilizado. Além de intensificar e aumentar a jornada de trabalho, essa forma de salário facilita ao empregador o uso e o descarte da força de trabalho. Deste modo, a forma da acumulação flexível reverbera no aprofundamento da exploração da força de trabalho (OBERHAUSER, 1990; ALVES, 2011; HARVEY, 2013).

Cardoso (2014) atesta que há uma rede de deslocamento entre o município baiano de Santaluz e Carmo do Rio Claro, município situado no sul do estado de Minas Gerais. Nesta perspectiva, a maioria dos trabalhadores que se deslocam temporariamente para o trabalho na cafeicultura em Carmo do Rio Claro, com destaque para o distrito de Vilelândia, procuram melhores remunerações. Os diminutos salários e a insuficiência de empregos no interior da Bahia são elementos que podem explicar a maior submissão e passividade de seus trabalhadores temporários frente à exploração do trabalho na cafeicultura, inclusive aceitando menores pagamentos.

Já em Nepomuceno, a maioria dos apanhadores de café é oriunda do próprio município, enquanto pequeno percentual é originário de municípios adjacentes, como Lavras, Coqueiral e Santana da Vargem (VILAS BOAS, 2016; CROCCO et al., 2017). De acordo com os proprietários fundiários nepomucenenses, a contratação de trabalhadores provenientes de municípios distantes é onerosa, pois demanda a oferta de 
infraestrutura de moradia aos safristas. Observou-se, em 2017 e 2018, crescimento da mão de obra disponível ao trabalho na colheita de café em Nepomuceno, uma vez que aumentou o número de trabalhadores que se ofereceram aos cafeicultores locais para desempenharem essa função.

No município de Alfenas, os cafeicultores estão priorizando a contratação da força de trabalho local ou de cidades próximas, pois o aumento da rigidez da legislação trabalhista, sobretudo no tocante às condições de trabalho, habitação e alimentação, encarece o custo da mão de obra oriunda de outras regiões. Destarte, os produtores municipais preferem contratar colhedores que não demandem residência em suas propriedades (SANTOS, 2011).

Em consonância com Santos (2011), Libanio, Calderaro e Vale (2011) constatam que em Alfenas, vários apanhadores de café são provenientes de municípios vizinhos, como Alterosa e Campo do Meio, uma vez que Alfenas possui um setor terciário desenvolvido, o qual oferta expressivo número de empregos para a população local, minorando a mão de obra disponível para o trabalho nas lavouras cafeeiras.

Em contrapartida, Guida (2010) ressalta que em Muzambinho, muitos colhedores de café são naturais do Paraná, do Sul da Bahia e do Norte de Minas Gerais. Nesta contextura, os cafeicultores arcam com as despesas relativas ao transporte e à habitação dos trabalhadores, fornecendo residência dotada de eletricidade, água encanada, móveis e eletrodomésticos.

Com relação ao deslocamento da mão de obra temporária na cafeicultura alfenense, Santos (2011) observa que a força de trabalho - composta majoritariamente por moradores de Alfenas ou de municípios adjacentes - é transportada em ônibus próprios na maioria das grandes propriedades, enquanto os pequenos cafeicultores não disponibilizam meios de transporte para os colhedores.

A despeito das semelhanças existentes entre os principais municípios cafeeiros da região geográfica intermediária de Varginha, existem singularidades derivadas de fatores econômicos, sociais, culturais e políticos. Nesta perspectiva, em Carmo Do Rio Claro, há grande presença de colhedores vindos do interior da Bahia, em virtude da rede de mobilidade sazonal instituída entre o município baiano de Santaluz e o distrito de Vilelândia (CARDOSO, 2014). 
No município de Muzambinho, a presença de apanhadores de outras regiões e estados também é significativa, mas se deve principalmente à maior capitalização dos cafeicultores locais e à infraestrutura consolidada de moradia e transporte dos trabalhadores (GUIDA, 2010). Em contrapartida, a maioria da mão de obra empregada na colheita cafeeira em Nepomuceno reside no próprio município ou é originária de cidades próximas, em virtude dos expressivos índices locais de desemprego e subemprego e da incipiência do capital dos pequenos cafeicultores, os quais são maioria no município (VILAS BOAS, 2016; CROCCO et al., 2017).

No município de Nepomuceno, alguns apanhadores de café trabalham em outros serviços após o período da safra, sobretudo em funções que demandam baixo grau de instrução formal, como serventes, atendentes de lojas, cabeleireiros e pedreiros. No entanto, muitos safristas não conseguem encontrar trabalho durante a entressafra. Tal fato ratifica que o desemprego estrutural constitui um sério problema na conjuntura municipal.

Segundo Guida (2010), o maior rigor na fiscalização e na aplicação da legislação no trabalho agrícola em Muzambinho resultou no crescimento da contratação formal de trabalhadores durante o período da colheita cafeeira. Todavia, a despeito dos avanços relativos à fiscalização do trabalho agrícola nos últimos anos, metade dos apanhadores de café entrevistados por Crocco et al. (2017) em Nepomuceno não possuem contratos formais de trabalho, negociando verbalmente a jornada de trabalho e o respectivo pagamento com o empregador. Durante o trabalho de campo efetuado entre 2015 e 2018, notou-se que a maioria dos colhedores foi contratada de maneira informal, sem a existência de quaisquer documentos comprobatórios de vínculo empregatício ou trabalhista. Como a assinatura de contrato de trabalho demanda o pagamento de encargos trabalhistas previstos na legislação, muitos cafeicultores preferem não formalizar a contratação dos apanhadores.

Entretanto, Ribeiro (2014) afirma que a fiscalização efetuada pelo Ministério do Trabalho e Emprego (MTE) possui inúmeras deficiências, pois o número de fiscais é insuficiente para o extenso conjunto de municípios que está sob sua responsabilidade. Após uma denúncia, os funcionários do MTE habitualmente demoram mais de um mês para investigá-la. Considerando o caráter temporário do trabalho na colheita, o apoio estatal reiteradamente chega atrasado para averiguar a ocorrência. 
80\% dos entrevistados por Ribeiro (2014) no município de Campo Belo trabalham de maneira informal na colheita de café, ou seja, apenas 20\% possuem carteira assinada. Assim, a maioria dos trabalhadores é privada de seus direitos. Ademais, os apanhadores de café reclamaram da ausência de fiscalização e da demora do MTE quando acionado para apurar alguma denúncia. Salienta-se que a ineficiência da fiscalização e a informalidade do trabalho na apanha da rubiácea favorecem o aprofundamento da exploração da mão de obra atuante na colheita, cujo pagamento é diretamente proporcional à produtividade alcançada.

No município de Nepomuceno, o colhedor usualmente é contratado em negociação direta com o proprietário fundiário. No entanto, em algumas situações, sobretudo em fazendas de maiores proporções, há a atuação de atravessadores ou intermediários, responsáveis pela fiscalização e contratação dos trabalhadores (CROCCO et al., 2017). Neste contexto, salienta-se que o salário por peça favorece a ação dos intermediários, cujo lucro é oriundo da diferença entre o preço pago pelo capitalista e a remuneração paga aos trabalhadores (MARX, 2013).

Além disso, os apanhadores de café na região intermediária de Varginha também padecem com a instabilidade do emprego, convivendo com o subemprego ou o desemprego, uma vez que trabalham por pequenos períodos em cada propriedade rural. Como muitos safristas não têm a garantia de emprego após o término da colheita, empenham-se ao máximo para alargar seus rendimentos, a fim de assegurar sua sobrevivência e a de seus familiares no restante do ano (RIBEIRO, 2014; VILAS BOAS, 2016).

Nos dizeres de Bacha (1991), os trabalhadores agrícolas temporários geralmente possuem empregos urbanos e rurais no decorrer do ano. Consequentemente, seu salário no campo é diretamente influenciado pelas receitas auferidas no trabalho urbano e pela oferta de empregos na cidade. Isto é, o número de postos de empregos urbanos e as remunerações ofertadas afetam diretamente os salários no campo, inclusive o salário por peça.

No município de Nepomuceno, com o aumento do desemprego nos anos de 2016 e 2017, houve crescimento da quantidade de trabalhadores que buscaram emprego sazonal na colheita do café, além da estagnação ou redução dos valores monetários pagos pela medida de café em algumas propriedades. Nesta conjuntura, a escassez de empregos 
formais e sua precariedade favorecem a intensificação da exploração nos trabalhos caracterizados pelo pagamento por produtividade, como no salário por peça.

No estudo efetivado por Ribeiro (2014) no município de Campo Belo, a média de balaios colhidos diariamente pelos apanhadores variou entre oito e dez unidades. Nesta seara, ressalta-se que cada balaio corresponde a uma medida de sessenta litros e o preço pago por balaio foi de oito reais $(\mathrm{R} \$ 8,00)$. Deste modo, o salário diário dos trabalhadores variou, em média, entre sessenta e quatro $(\mathrm{R} \$ 64,00)$ e oitenta reais $(\mathrm{R} \$ 80,00)$. Apenas um trabalhador, cuja habilidade e força física foram enaltecidas pelos demais, conseguiu colher cerca de quinze balaios por dia, equivalendo a uma remuneração diária de 120 reais ( $\$$ \$ 120,00). Neste panorama, Marx (2013) salienta que o pagamento na modalidade do salário por peça oscila de acordo com a diversidade individual dos trabalhadores e suas diferentes produtividades. Assim, as remunerações variam segundo a destreza, eficiência, força e resistência de cada trabalhador.

De acordo com Sigaud (1977), a mudança do salário diário, pago pelo dia de serviço, para o pagamento por produtividade, como ocorre no salário por peça e na colheita do café na maioria dos municípios sul-mineiros, promove a intensificação do trabalho e a contração dos salários pagos aos trabalhadores. Neste contexto, o proprietário fundiário obtém vantagem, uma vez que seus lucros e a produtividade de suas terras são ampliados. Contudo, o aumento de seus rendimentos ocorre em decorrência da exploração do trabalho alheio, da redução das remunerações e da degradação da qualidade de vida do trabalhador. Destarte, há precarização tanto das condições laborais, quanto das condições de vida dos trabalhadores agrícolas.

Em pesquisa realizada no município de Divisa Nova, Raimundo e Vale (2016) destacam a predominância do pagamento por produtividade e a insalubridade do trabalho dos apanhadores de café. Ademais, salientam a função exercida pelas mulheres na cafeicultura municipal, as quais, na maioria dos casos, possuem dupla jornada de trabalho, labutando tanto na colheita do café, quanto com os afazeres domésticos. Agravando a situação, Ribeiro (2014) sublinha que, em âmbito geral, a produtividade do trabalho feminino é inferior à do masculino na colheita. Já em Campo Belo, alguns trabalhadores afirmaram que quando estão de férias de seu emprego formal, trabalham na colheita da rubiácea. Deste modo, em virtude de seus parcos rendimentos, cidadãos abdicam de suas férias com o objetivo de maximizar seus vencimentos (RIBEIRO, 2014). 
De acordo com Ribeiro (2014), o apanhador de café almoça rapidamente com o intuito de aumentar a eficiência de seu trabalho e, por conseguinte, avolumar sua remuneração. Nesta esfera, Marx (2013) salienta que, em virtude do próprio caráter do salário por peça, o operário aplica intensamente sua força de trabalho, uma vez que seus ganhos dependerão diretamente de sua produtividade. Todavia, o trabalhador não amplia somente a intensidade de seu trabalho, como também majora sua duração temporal, fato verificado na cafeicultura da região geográfica intermediária de Varginha.

Em consonância com Marx (2006; 2011), pode-se afirmar que no salário por peça, característico da cafeicultura da região geográfica intermediária de Varginha, o trabalho foi convertido em mercadoria, a qual é paga conforme a produtividade obtida. Além disso, o resultado da produção é algo estranho ao apanhador, pois não pertence a ele, mas ao proprietário das terras. Neste cenário, o trabalho do colhedor é alienado, pois não sacia diretamente suas necessidades fisiológicas, somente providencia recursos financeiros para a aquisição de víveres imprescindíveis, como os gêneros alimentícios.

Desta maneira, o trabalho alienado e estranhado está intimamente associado à propriedade privada e ao assalariamento, fenômeno observado na cafeicultura dos municípios analisados. Além disso, em virtude do processo de alienação, o trabalhador pode atribuir a si a responsabilidade de sua pobreza, justificando que seu desempenho durante a colheita foi insuficiente para a obtenção de um salário que lhe propiciasse melhores condições de vida. Neste panorama, elementos fundamentais para a compreensão da pobreza rural, como a propriedade dos meios de produção e o valor das remunerações pagas, são desconsiderados.

\section{Considerações finais}

Conforme foi apresentado neste artigo, a forma pretérita de assalariamento do capitalismo, denominada salário por peça por Karl Marx, assume importância considerável nos dias atuais por promover níveis crescentes de exploração e maior engajamento do trabalhador com a racionalidade produtiva que, consequentemente, majoram os lucros do capital. Neste sentido, a cafeicultura da região geográfica intermediária de Varginha é caracterizada pelo emprego de mão de obra temporária (sazonal) e pelo pagamento por produtividade, constituindo uma forma específica e 
amplamente difundida do salário por peça no meio rural. Com o intuito de aumentar seus rendimentos financeiros nesta forma de assalariamento, os apanhadores de café exploram a si mesmos, intensificam seu trabalho e aumentam suas jornadas diárias, submetendo-se a uma carga deletéria, precária e flexível de trabalho, em condições muitas vezes insalubres e inadequadas.

Em alguns municípios, como Nepomuceno e Alfenas, predominam trabalhadores provenientes do próprio município ou de cidades adjacentes, enquanto em Carmo do Rio Claro, Muzambinho e Campos Gerais, há expressiva presença de safristas oriundos de outras regiões e estados. Muitos destes trabalhadores migrantes residem em localidades pobres e com falta de oportunidades de emprego, e frequentemente se deslocam em busca de oportunidades e aceitam com maior facilidade condições exploratórias e precárias de trabalho. Em ambos os casos, o pagamento por produtividade através do salário por peça promove a ampliação da exploração do trabalho na cafeicultura, uma vez que o aumento da produtividade reverbera em decréscimos no salário por peça e em prejuízos à saúde do trabalhador. Nota-se, portanto, o constante aumento da mais-valia absoluta e relativa extraída no trabalho agrícola no Sul de Minas Gerais, pois com os acréscimos na produtividade - resultantes principalmente da inserção da derriçadeira portátil na colheita - e a intensificação do trabalho, ocorreu a diminuição dos salários pagos aos apanhadores de café e o crescimento do valor criado pelo seu trabalho e apropriado pelos proprietários dos meios de produção.

Por fim, esta investigação procurou contribuir criticamente para o entendimento das características da cafeicultura da região geográfica intermediária de Varginha-MG a partir da relação de suas condições produtivas e trabalhistas com a forma de assalariamento por produtividade, típica do modo de produção capitalista.

\section{Notas}

\footnotetext{
${ }^{1}$ Marx exemplifica esse fato a partir do trabalho dos tipógrafos e dos carpinteiros navais: “Os tipógrafos de Londres trabalham geralmente por peça, enquanto o salário por tempo constitui a exceção entre eles. $\mathrm{O}$ contrário ocorre com os tipógrafos nas províncias, onde o salário por tempo é a regra e o salário por peça, a exceção. Os carpinteiros navais no porto de Londres são pagos por peça; nos demais portos ingleses, por tempo" (MARX, 2013, p. 759).

${ }^{2}$ Como, por exemplo, as novas formas de gestão, do modelo de acumulação flexível, baseadas nos team works e pautados no controle e no salário por resultado. Falsamente apresentadas como novidades, essas formas de pagamento são comumente chamadas de bonificações adicionais por desempenho, bônus de produtividade e participação nos lucros por resultados (ALVES, 2011).
} 
${ }^{3}$ Sobre a instabilidade e a comparação do salário por peça e do salário por tempo, Marx apresenta a passagem de um texto favorável aos landlords [proprietários fundiários] e arrendatários: "A maior parte das operações agrícolas é executada por pessoas contratadas por dia ou por peça. Seu salário semanal é de mais ou menos 12 xelins, e ainda que se possa pressupor que um homem trabalhando por peça, sob um estímulo maior, ganhe 1 ou mesmo 2 xelins a mais do que se fosse pago por semana, conclui-se, no entanto, ao calcular sua receita total, que sua perda de ocupação no decorrer do ano contrapesa esse ganho adicional" (MARX, 2013, p. 765).

${ }^{4} \mathrm{O}$ valor da medida ou do balaio de café corresponde a sessenta litros. O preço pago aos apanhadores varia de acordo com a escala espaço-temporal. De acordo com Ribeiro (2014), os cafeicultores pagaram oito reais $(\mathrm{R} \$ 8,00)$ no balaio de café colhido no município de Campo Belo. Já em Nepomuceno, Crocco et al. (2017) observam que o valor pago pela medida de café variou entre doze $(\mathrm{R} \$ 12,00)$ e quinze reais $(\mathrm{R} \$$ $15,00)$ nos anos de 2016 e 2017. Durante o trabalho de campo realizado em Nepomuceno entre os anos de 2015 e 2018, a quantia financeira paga por medida colhida oscilou entre dez $(R \$ 10,00)$ e quinze reais $(R \$$ $15,00)$

${ }^{5} \mathrm{O}$ emprego da derriçadeira portátil, vulgarmente conhecida como "mãozinha" ou "mão mecânica" pelos colhedores, caracteriza a colheita semimecanizada em diversos municípios da região geográfica intermediária de Varginha, como Alfenas, Campo Belo, Campos Gerais, Carmo do Rio Claro e Nepomuceno.

${ }^{6}$ Com base em Marx (2011; 2013), compreende-se a mais-valia como o sobretrabalho apropriado pelo capitalista e não pago ao trabalhador, isto é, a diferença entre o valor criado por seu trabalho e a remuneração recebida, uma vez que o excedente da produção é apossado pelos detentores do capital.

\section{REFERÊNCIAS}

ALVES, Francisco. Por que morrem os cortadores de cana? Saúde e Sociedade, São Paulo, v. 15, n. 03, p. 90-98, 2006.

ALVES, Giovanni. Trabalho e subjetividade: o espírito do toyotismo na era do capitalismo manipulatório. São Paulo: Boitempo, 2011.

BACHA, Carlos José Caetano. Determinação dos salários na agricultura. Revista Brasileira de Economia, Rio de Janeiro, v. 45, n. 03, p. 441-471, 1991.

CARDOSO, Haroldo Junior Martins. Análise da mobilidade populacional entre os Municípios de Carmo do Rio Claro-MG e Santaluz-BA. 2014. Trabalho de Conclusão do Curso (Licenciatura em Geografia). Universidade Federal de Alfenas, Alfenas, 2014.

COALIZAÇÃO DO CAFÉ. Café: vida, produção e trabalho - agricultores familiares e assalariados rurais. Florianópolis: Instituto Observatório Social, 2004.

COSTA, Cinthia Cabral da; POPPI, Luciana. Impactos sócio-econômicos do sistema de derriça mecanizado portátil na colheita de café de montanha no Brasil. Boletim de Pesquisa e Desenvolvimento, Embrapa/São Carlos, n. 36, p. 01-26, 2012.

COULIS, Jonathan. E. Rooted in Coffee - Deregulation, Economic Crisis and Restructuring Power in the Brazilian Coffee Sector: How Small-Scale Coffee Producers Responded to the Coffee Crisis in Sul de Minas. 2011. Dissertação (Mestrado em Artes em História) - Departamento de História, Universidade de Guelph, Ontario, Canadá, 2011. 
CROCCO, Fábio Luiz Tezini; VILAS BOAS, Lucas Guedes; TONELLI, Gianni; MARQUES, Victor Hugo Mendes Siqueira. Café, terra e trabalho no Município de Nepomuceno-MG. Revista Pegada, Presidente Prudente, v. 18, n. 03, p. 78-100, 2017.

GUANAIS, Juliana Biondi. Pagamento por produção, intensificação do trabalho e superexploração na agroindústria canavieira brasileira. 2016. Tese (Doutorado em Sociologia). Universidade Estadual de Campinas, Campinas, 2016.

GUIDA, Larissa Chiulli. As Cidades do Agronegócio no Sul de Minas: A Constituição de Muzambinho como uma Cidade Funcional à Produção Cafeeira. In: CONGRESSO BRASILEIRO DE ORGANIZAÇÃO DO ESPAÇO, I., e SEMINÁRIO DE PÓSGRADUAÇÃO EM GEOGRAFIA DA UNESP X., 2010, Rio Claro. Anais [...]. Rio Claro: UNESP, 2010. p. 2936-2951.

HARVEY, David. Os limites do capital. Tradução: Magda Lopes. São Paulo: Boitempo, 2013.

INSTITUTO BRASILEIRO DE GEOGRAFIA E ESTATÍSTICA. Divisão Regional do Brasil em Regiões Geográficas Imediatas e Regiões Geográficas Intermediárias. Rio de Janeiro: IBGE, 2017.

LIBANIO, Cochise Ricci; CALDERARO, Rodrigo Alexandre Pereira; VALE, Ana Rute do. Do pequeno ao grande: o contexto da cafeicultura no Sul de Minas e sua questão agrária. Revista Discente Expressões Geográficas, Florianópolis, v. 07, n. 07, p. 155-173, 2011.

LUKÁCS, György. História e consciência de classe: estudos sobre a dialética marxista. São Paulo: Martins Fontes, 2003.

MARX, Karl. Manuscritos econômico-filosóficos. Tradução: A. Marins. 2. reimp. São Paulo: Martin Claret, 2006.

MARX, Karl. Gundrisse: manuscritos econômicos de 1857-1858: esboços da crítica da economia política. Tradução: M. Duayer, N. Schneider, A. H. Werner e R. Hoffman. Rio de Janeiro: Boitempo/UFRJ, 2011.

MARX, Karl. O Capital: crítica da economia política. Livro I: o processo de produção do capital. Tradução: Rubens Enderle. São Paulo: Boitempo, 2013.

MELLO; Carolina Motta de; SILVA, Luiz Felipe. Fatores associados à intoxicação por agrotóxicos: estudo transversal com trabalhadores da cafeicultura no sul de Minas Gerais. Epidemiologia e Serviços de Saúde, Brasília, v. 22, n. 04, p. 609-620, 2013.

MERGULHÃO, Amanda Duarte. Os fluxos, as relações e os agentes envolvidos na produção e comercialização do café produzido atualmente no Brasil. Revista da Anpege, Dourados, v. 13, n. 22, p. 57-85, 2017. 
OBERHAUSER, Ann M. Social and spatial patterns under fordism and flexible accumulation. Antipode, v. 22, n. 03, p. 211-232, 1990.

OLIVEIRA, Ariovaldo Umbelino de. Modo capitalista de produção, agricultura e reforma agrária. São Paulo: FFLCH/Labur, 2007.

PEREIRA, Daniele de Mesquita. O café e a migração no Sul de Minas: a mão de obra migrante na cafeicultura de Campos Gerais - MG. 2011. Trabalho de Conclusão do Curso (Licenciatura em Geografia). Universidade Federal de Alfenas, Alfenas, 2011.

RAIMUNDO, Glaucione; VALE, Ana Rute do. As mulheres colhedoras de café no Município de Divisa Nova-MG e as mudanças nas leis trabalhistas. In: ENCONTRO NACIONAL DE GEOGRAFIA AGRÁRIA, XXIII., 2016, São Cristóvão. Anais [...]. São Cristóvão: UFS, 2016. p. 01-12.

RIBEIRO, Jeovana Nunes. O trabalho rural e a sazonalidade do café: um estudo sobre assalariados do município de Campo Belo-MG. 2014. Tese (Doutorado em Serviço Social). Programa de Pós-Graduação em Serviço Social, Universidade Estadual Paulista Júlio de Mesquita Filho, Franca, 2014.

SAMSEL, Anthony; SENEFF, Stephanie. Glyphosate, pathways to modern diseases IV: cancer and related pathologies. Journal of Biological Physics and Chemistry, v. 15, p. 121-159, 2015.

SANTOS, Henrique Faria dos. A outra face do agronegócio globalizado e as desigualdades socioespaciais: estudo de caso com a cafeicultura moderna no Município de Alfenas-MG. 2011. Trabalho de Conclusão do Curso (Licenciatura em Geografia). Universidade Federal de Alfenas, Alfenas, 2011.

SANTOS, Henrique Faria dos. Modernização da agricultura e relação campo-cidade: uma análise a partir do agronegócio cafeeiro no município de Alfenas. Caminhos de Geografia, Uberlândia, v. 15, n. 51, p. 154-171, 2014.

SIGAUD, Lygia. A percepção do salário entre trabalhadores rurais. In: PINKSY, Jaime (org.). Capital e trabalho no campo. São Paulo: Hucitec, 1977. p. 49-67.

SILVA, Maria Aparecida de Moraes. Errantes do fim do século. São Paulo: Unesp, 1999.

SILVA, Maria Aparecida de Moraes. Trabalho rural: as marcas da raça. Lua Nova, São Paulo, n. 99, p. 139-176, 2016.

SILVA, Maria Aparecida de Moraes.; BUENO, Juliana Dourado.; MELO, Beatriz Medeiros de. Quando a máquina "desfila", os corpos silenciam: tecnologia e degradação do trabalho nos canaviais paulistas. Contemporânea, São Carlos, v. 04, n. 01, p. 85$115,2014$. 
STOLCKE, Verena. Cafeicultura: homens, mulheres e capital (1850-1980). São Paulo: Brasiliense, 1986.

VALE, Ana Rute do; CALDERARO, Rodrigo Alexandre Pereira; FAGUNDES, Francielly Naves. A cafeicultura em Minas Gerais: estudo comparativo entre as Regiões Triângulo Mineiro/Alto Paranaíba e Sul/Sudoeste. Campo-Território, Uberlândia, v. 09, n. 18, p. 01-23, 2014.

VILAS BOAS, Lucas Guedes. A questão agrária no município de Nepomuceno-MG. Campo-Território, Uberlândia, v. 11, n. 24, p. 344-373, 2016.

VILAS BOAS, Lucas Guedes. Segurança alimentar no campo e na cidade em Nepomuceno-MG. Revista Tamoios, São Gonçalo, v. 13, n. 01, p. 50-71, 2017.

Recebido em 23/09/2019.

Aceito para publicação em 09/04/2020. 